\title{
Tobacco price elasticity in Serbia: evidence from a middle-income country with high prevalence and low tobacco prices
}

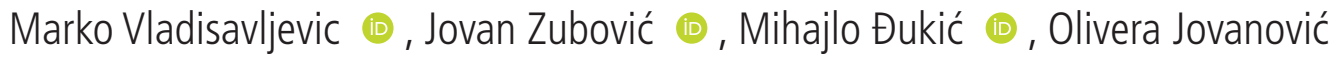

- Additional material is published online only. To view please visit the journal online (http://dx.doi.org/10.1136/ tobaccocontrol-2019-055262).

Institute of Economic Sciences, Belgrade, Serbia

\section{Correspondence to}

Marko Vladisavljevic, Institute of Economic Sciences, Belgrade 11000, Serbia;

marko.vladisavljevic@ien.bg. ac.rs

Received 1 July 2019 Revised 1 October 2019 Accepted 7 December 2019 Published Online First 26 August 2020
Check for updates

(C) Author(s) (or their employer(s)) 2020. No commercial re-use. See rights and permissions. Published by BMJ.

To cite: Vladisavljevic $\mathrm{M}$ Zubović J, Đukić M, et al. Tob Control

2020;29:s331-s336.

\section{ABSTRACT}

In this paper, we use Deaton's demand model and Household Budget Survey data from 2006 to 2017 to provide a first robust and reliable estimate of cigarettes price elasticity for Serbia. The case of Serbia is particularly interesting and important as it provides evidence for a country in which tobacco market is characterised by the high tobacco consumption, low prices and large perceived impact of multinational tobacco companies on public revenues, export and employment, given their considerable cigarette production in Serbia. The price elasticity of cigarettes is estimated at -0.639 , in line with the previous estimates for the low-income and middle-income countries. Estimated negative cigarettes price elasticity for Serbia suggests that tobacco tax policy could be used effectively to reduce cigarette consumption in Serbia, which could lower the harmful health effects of cigarettes. Furthermore, a calculation based on the estimated elasticity suggests that increasing tobacco taxes could also have positive fiscal effects, as the expected revenue from the taxes would increase.

\section{INTRODUCTION}

While increases of tobacco taxes have frequently been viewed as an essential instrument for tobacco control, the effects of such policies depend on consumer responses to changes in price, that is, on tobacco price elasticities. Previous studies indicated negative tobacco price elasticities, typically ranging from -0.25 to -0.5 for high-income countries, ${ }^{1}$ while they clustered around -0.5 for low-income and middle-income countries, although the estimates for the former are more variable. ${ }^{1-3}$

In this study, we aim to provide the first reliable and robust tobacco price elasticity estimate for Serbia while similar studies are currently nonexistent for the wider area of Western Balkans. Estimation of the price elasticity for Serbia is an important and interesting case study for at least three reasons. First, Serbia is a country with one of the highest cigarette prevalence rates in Europe, with $29.2 \%$ of daily smokers, while the comparative rate for the EU is $18.4 \%$ as per European Health Survey. ${ }^{4}$ Similarly, the smoking intensity is also on a high level as about $8.7 \%$ of the population in Serbia smokes 20 or more cigarettes per day, while this share is about $5.8 \%$ in the EU. Other estimates indicate that when both daily and occasional smokers are included, the prevalence rate reaches about $38 \% .^{5}$ The prevalence rate is also high among the youth, with the overall level of $16.2 \%,{ }^{6}$ while smoking cessation is not common. ${ }^{5}$

Second, although real prices of cigarettes have been increasing, they are relatively low, as the average weighted price in Serbia in 2018 stood at $€ 2.05$ per pack, ${ }^{7}$ compared with the EU-28 average of $€ 4.8 .^{8}$ In 2018, total tax burden, at the average weighed price per cigarette pack stood at $€ 1.59$, consisting of specific excise (€0.58), ad valorem excise (33\%—€0.69), and 20\% value-added tax (VAT, €0.34). ${ }^{9}$ Serbia introduced a mixed excise tax system with an ad valorem excise tax (based on retail prices) and a specific excise tax in 2005 . The excise tax policy defined in the Excise Law includes a gradual increase in specific excises, by about $4 \%$ per year nominally, ${ }^{9}$ while cigarette prices were growing at about four times higher rate (by the average of 15\% per year between 2006 and 2017), resulting in an increasing share of netof-tax prices in total price. The excise tax of about $61 \%$ of the weighted average retail price is low, as WHO's framework convention on tobacco control, that Serbia signed in 2017 suggests that excise tax should be at least about $70 \% .^{1011}$ Furthermore, the current excise burden of about $€ 1.25$ per pack of 20 cigarettes is about $30 \%$ lower than the minimum excise duty of $€ 1.8$ per pack recommended by the EU and Serbia will, in the process of harmonisation with the EU standards, need to increase the excises to this level. Although this rule is not obligatory, all the EU member states have set the excise taxes to the recommended level or higher.

Third, the tobacco market in Serbia is characterised by three major privatisations of tobacco companies by large international companies (PMI, JTI and BAT) and one Greenfield investment within the last 15 years. Factories operating in Serbia produced 37.5 billion sticks of cigarettes in $2017,{ }^{12}$ making Serbia the fourth largest producer of cigarettes in Europe. ${ }^{13}$ Serbian production accounted for $7.7 \%$ of the total production in Europe (excluding Russia) in 2017, making Serbia the fourth larger European producer after Germany (31\%), Poland (23\%) and Romania (14\%). The export of cigarettes from Serbia has increased by 10 -fold since $2007 .{ }^{12}$ The tobacco industry, perceived as an important source of public revenues, a large exporter and employer, enjoys strong Government support, including but not limited to the policy of slow increase of the excise duties. Tobacco industry pressure for slower rise of excises has been defended by potential decrease in budget revenues and reduction of employment and investments. However, there is a reasonable doubt whether this impact is evidence 
based, as employment in the tobacco sector is on a long-term decreasing trend, and currently stands at $0.06 \%$ of total employment. ${ }^{12}$ Similarly, research conducted in other countries suggests that the importance of the tobacco industry has been largely exaggerated. ${ }^{14}$

Against this background, the aim of our paper is to estimate the cigarettes price elasticity in Serbia. We use Deaton's ${ }^{15}$ demand model and nationally representative Household Budget Survey (HBS) data from 2006 to 2017 to estimate the price elasticity of quantity of cigarette demand in Serbia. Deaton's model is a theoretically based demand model which estimates the price elasticity, by using unit values as a proxy for price, and a structure imposed by a weak separability assumption, to accounting for the effect of the quality.

In addition to providing first reliable estimate of price elasticity for Serbia, this research provides estimates of consumption and fiscal revenues responses to a sharper increase of excise tax, based on the scientific model of demand elasticity and the nationally representative data. Our estimate can then be contrasted with the tobacco-industry-funded argument of the adverse effects on the public revenue and provide the Government of Serbia key inputs to formulate tobacco taxation policy which will have a positive impact for all of its citizens.

\section{DATA AND STYLISED FACTS}

In order to estimate the price elasticity of the cigarette consumption, we use the HBS data for years from 2006 to 2017. HBS is a nationally representative survey, conducted annually by the Statistical Office of the Republic of Serbia (SORS). The survey is conducted as a repeated cross-section (without a panel structure) and it is used for the calculation of weights for Consumer Price Indices, but also to monitor the national consumption trends and the calculation of the absolute poverty rates. HBS is conducted in all European countries with a comparable methodology, coordinated by Eurostat. ${ }^{16}$ This is the only survey in Serbia which provides detailed information on household consumption, as well as on individual and household characteristics, which are required in order to estimate Deaton's model. ${ }^{17}$ In total, there were 62054 households out of which about 39\% have positive monthly expenses on cigarettes. Households with positive expenditure on average buy about 34 packs per month, with smoking intensity decreasing from 39 packs in 2006 to 27 packs in 2017.

Unit values, used as proxy for prices in the Deaton model, are calculated as a ratio of household expenditure on cigarettes and the number of cigarette packs purchased by the household during 1 month. Budget share, another important variable in the model, is calculated as a ratio of monthly household expenditure on cigarettes and the total household expenditure. All expenditure variables are deflated to their real values from 2006, by using Consumer Price Index (available online from the SORS website http://www.stat.gov.rs/).

\section{ECONOMETRIC MODEL AND METHODS Deaton's model}

Deaton demand model is a widely used, theoretically based consumer behaviour model. Due to the length of the explanation, we are only able to give the intuition behind Deaton's theoretical model. Interested reader can find the full description in Deaton's original work cited in this paper. Alternative approach in the estimation of the price elasticity is a macrolevel time series approach, which relies on one measure of price and consumption (and other control variables) per observation period. However, these models have been criticised for the lack a theoretical background and arbitrary choice of functional form and variables. One important issue typically not covered by ad-hoc models is the issue of quality substitution (explained later in the text), which is crucial to identification of the model. In addition, time series are typically not long enough to produce reliable estimates. Previous estimates of the price elasticities for Serbia cannot be considered reliable exactly for these reasons, as they are based on an ad-hoc estimation model and only 15 observations $^{18}$.

In the Deaton's model, total expenditure on goods is defined as a product of quantity, quality and prices of a good. Given its definition as the ratio between the total expenditure and the quantity purchased, the unit value represents the product of quality and price. ${ }^{19}$ The starting point of Deaton's model is two equations ${ }^{20}$ :

$$
\begin{gathered}
w_{b c}=\alpha^{0}+\beta^{0} \ln x_{h c}+\gamma^{0} \cdot z_{b c}+\theta \ln p_{c}+\left(f_{c}+u_{c b}^{0}\right) \\
\ln v_{b c}=\alpha^{1}+\beta^{1} \ln x_{b c}+\gamma^{1} \cdot z_{b c}+\psi \ln p_{c}+u_{b c}^{1}
\end{gathered}
$$

where indices $b$ and $c$ represent households and clusters, respectively. The dependent variables in equations (1) and (2) are $w_{b c}$, share of the household budget spent on cigarettes (in percentages), and natural logarithm of $v_{b c}$, cigarette unit values. On the right side of both equations, we have $x_{b c}$-total expenditures of the household $h$ in cluster $c, z_{h c}$-other household characteristics, $p_{c}$-price of the cigarettes in cluster c, while $u_{c b}^{0}$ and $u_{b c}^{1}$ represent the error term. Finally, in equation (1), $f_{c}$ are the cluster-level effects on the budget share, which are assumed to be uncorrelated with the price effect on the budget share, and are introduced to capture random variation in demand of clusters. ${ }^{20}$

As the model assumes that all households within a cluster (typically a small territory unit, such as municipality or village) face the same market price, within-cluster variations in purchases depend only on total household expenditure and characteristics and reflect the variation in good's quality. On the other hand, cross-cluster variations in purchase are due to genuine price variations, resulting from cluster differences in transportation costs and taxes. Cluster variation in costs and taxes, verified via genuine variation of prices across clusters, then implicitly serve as an instrument for the identification of the price elasticities. ${ }^{17}$

In the unit value equation (equation (2)), coefficient $\beta^{1}$ represents total expenditure elasticity, while $\psi$ represents the price elasticity of unit values. When the cigarette prices change, with unchanged budget assumed, households can either decrease their cigarette consumption or switch to a less expensive brand and keep their consumption at the same level. The latter is referred to as the quality shading. If there is no quality shading, the value of $\psi$ should be equal to 1 (as the change of the unit value would correspond to change of the price) and $\beta^{1}$ approximately equal to zero. On the other hand, in the presence of the quality shading, $\psi$ will be less than 1 (unit value change will be slower than the change of the price) and $\beta^{1}$ higher than zero. The information from the unit value equation on quality shading is later used in the model to correct the price elasticity.

\section{Estimation of the model}

Since the prices are not observed, the parameters $\theta$ and $\psi$ cannot be directly estimated from equations (1) and (2). However, the assumption that the market prices do not vary within the cluster (hence the absence of the index $h$ ) enables consistent estimates of the remaining parameters by using cluster 
deviation-from-the-mean approach which cancels the effect of the prices from the equations. Therefore, in the first stage, we estimate the parameters from equations (1) and (2) by including dummy variables for each cluster in the regression, which yields identical estimates as deviation-from-the-mean approach. ${ }^{21}$

In the second stage, we use the estimates from the first stage to remove the effects of the total household expenditure and other household characteristics from the budget shares and the unit values. Variables constructed in this way are then used to create cluster averages of budget shares and unit values, which now be written as

$$
\begin{gathered}
y_{c}^{0}=\alpha^{0}+\theta \ln p_{c}+f_{c}+u_{c}^{0} \\
y_{c}^{1}=\alpha^{1}+\psi \ln p_{c}+u_{c}^{1}
\end{gathered}
$$

The estimation of the parameter $\theta$, which represents the price semielasticity, is not possible as the price is not observed. However, Deaton uses the fact that price is present in both equations to obtain a relationship between the budget share and unit values. The result is parameter $\phi$, hybrid of price and quality elasticity, which is equal to $\psi^{-1} \theta{ }^{20}$

In the third stage, we introduce the assumption on weak separability and the definition of the budget share as the product of quantity of cigarettes and unit value divided by the total expenditures. From there, the parameter $\theta$ can be estimated as ${ }^{20}$ :

$$
\hat{\theta}=\hat{\phi} /\left[1+(w-\hat{\phi}) \frac{\hat{\beta}^{1}}{\hat{\beta}^{0}+w\left(1-\hat{\beta}^{1}\right)}\right]
$$

where $\beta^{1}$ and $\beta^{0}$ are coefficients estimated in equations (1) and (2), while $w$ is the average value of the budget share. Value of $\psi$ is then equal to $\phi^{-1} \theta$. From there, price elasticity of demand can be estimated $\mathrm{as}^{20}$ :

$$
\hat{\epsilon}_{p}=\left(\frac{\hat{\theta}}{w}\right)-\hat{\psi}
$$

Similarly, since in equation (1) we have budget shares and not logarithm of quantity, parameter $\beta^{0}$ does not estimate the expenditure elasticity of demand. Instead, the total elasticity of expenditure can be estimated $\mathrm{as}^{20}$ :

$$
\hat{\epsilon}_{x}=1-\hat{\beta}^{1}+\left(\frac{\hat{\beta}^{0}}{w}\right)
$$

We follow John, ${ }^{19}$ and impose symmetry restrictions on demand function to increase the precision of the parameter estimates. Furthermore, the system is completed by adding a composite commodity which accounts for all other goods that are purchased from the household budget. Due to the calculation procedure, standard errors of price elasticity cannot be taken directly from the regression analyses. Instead, we use the bootstrapping procedure with 1000 replications to calculate the SE of the estimated price elasticity.

\section{Cluster definition, vector of covariates and the model assumptions}

We define clusters based on the information on municipalities and years; that is, the cluster is defined as a municipality $x$ in the year $t$. According to this definition, we generate 1823 clusters, which on average include about 68 households. The first stage regression, as suggested in the literature, ${ }^{17} 1920$ controlled for total expenditures (ln), as well as household size (ln), urban/ rural status, age and gender composition of the household, as well as the mean and maximum level of education of the household members. We additionally control for the household type by economic activity, by taking the 'maximum' activity of the household members and split the households to four types (1)
Table 1 Descriptive statistics of variables used in the first-stage regression

\begin{tabular}{llcccc}
\hline & Obs. & Mean & Std dev. & Min & Max \\
\hline Unit value, cigarettes & 24143 & 81.34 & 27.30 & 14.17 & 208.88 \\
\hline Budget share, cigarettes & 61889 & 0.03 & 0.05 & 0.00 & 0.51 \\
\hline Total expenditure & 61889 & 3.25 & 2.07 & 0.08 & 14.26 \\
Household size & 61889 & 2.91 & 1.65 & 1 & 20 \\
Male ratio & 61889 & 0.46 & 0.28 & 0 & 1 \\
Adult ratio & 61889 & 0.92 & 0.16 & 0.14 & 1 \\
Mean education & 61889 & 10.34 & 2.84 & 2 & 20 \\
\hline Maximum education & 61889 & 11.48 & 3.13 & 2 & 20 \\
\hline Rural settlements & 61889 & 0.59 & 0.49 & 0 & 1 \\
Household type & & & & & \\
$\quad$ Employed & 61889 & 0.62 & 0.49 & 0 & 1 \\
\hline Self-employed & 61889 & 0.13 & 0.34 & 0 & 1 \\
\hline Pensioners & 61889 & 0.34 & 0.48 & 0 & 1 \\
\hline Unemployed & 61889 & 0.04 & 0.20 & 0 & 1 \\
\hline
\end{tabular}

Authors' calculation based on the Household Budget Survey data.

employed, (2) self-employed, (3) pensioner and (4) unemployed. Descriptive statistics of the variables are presented in table 1.

We restrict our analysis to the analysis of the expenditures on cigarette packs, therefore excluding cut tobacco. This is done for two reasons. First, the implementation of Deaton's model implies the use of the unit values so the aggregation of the expenditures on different tobacco products was not possible. Second, according to HBS data, less than 3\% of the households have positive cut tobacco consumption. Additionally, we exclude households whose total household expenditure is $5 \mathrm{SD}$ higher or lower than the mean expenditure in the overall sample, to avoid the effect of the extreme values on our estimates. The total sample for the regression analysis amounts to 61889 households.

\section{RESULTS}

Time and regional variation in budget shares and unit values

One of the assumptions of Deaton's model is that unit values and budget shares have sufficient variability over the clusters. As we define clusters as municipality $\mathrm{x}$ in year $\mathrm{t}$, in order to demonstrate the variability of the unit values and budget shares, similarly to Deaton, ${ }^{20}$ we regress them on year and region dummies. Table 2 presents the results of regression analysis which indicate significant time and regional variation of the real unit values of cigarettes and budget shares. The average unit value for a cigarette pack paid by the household in Belgrade in 2006 stood at about $57 \mathrm{RSD}$, with other regions paying lower prices of cigarettes. The average real unit value of the cigarettes has doubled from 2006 to 2017. The trends of the unit values and official statistics on tobacco consumer price index (CPI) are very similar. According to tobacco CPI the prices have increased by 2.4 times (in real terms), while the unit value prices have increased by 2.3 times (also in real terms).

On the other hand, the budget share regression indicates that the households in Belgrade in 2006 spent about 4.8\% (row constant in the column budget share) of their budget on cigarettes (conditional on having positive cigarette expenses), with other regions spending more on average, with significant increase over the years.

\section{Estimation of the Deaton model}

Table 3 presents the results of the estimation of equations (1) and (2). We first comment on the results of the unit values equation. 
Table 2 Regional and time variation of cigarette unit values and budget shares

\begin{tabular}{|c|c|c|c|c|}
\hline $\begin{array}{l}\text { Variables } \\
\text { Region }\end{array}$ & \multicolumn{2}{|c|}{$\begin{array}{l}\text { Unit value } \\
\text { (per cigarette pack) }\end{array}$} & \multicolumn{2}{|c|}{ Cigarette budget share (in \%) } \\
\hline Belgrade & Omitted & & & \\
\hline Vojvodina & $-8.440^{* * *}$ & $(0.275)$ & $0.008^{* * *}$ & $(0.001)$ \\
\hline West Serbia & $-5.957^{* * *}$ & $(0.268)$ & $0.012^{* * *}$ & $(0.001)$ \\
\hline East Serbia & $-8.210^{* * *}$ & $(0.289)$ & $0.020^{* * *}$ & $(0.001)$ \\
\hline \multicolumn{5}{|l|}{ Year } \\
\hline 2006 & Omitted & & & \\
\hline 2007 & $6.671^{* * *}$ & $(0.434)$ & $0.009 * * *$ & $(0.002)$ \\
\hline 2008 & $7.316^{* * *}$ & $(0.443)$ & $0.007^{* * *}$ & $(0.002)$ \\
\hline 2009 & $11.344^{* * *}$ & $(0.450)$ & $0.012^{* * *}$ & $(0.002)$ \\
\hline 2010 & $14.623^{* * *}$ & $(0.459)$ & $0.013^{* * *}$ & $(0.002)$ \\
\hline 2011 & $17.141^{* * *}$ & $(0.461)$ & $0.017^{* * *}$ & $(0.002)$ \\
\hline 2012 & $24.313^{* * *}$ & $(0.465)$ & $0.016^{* * *}$ & $(0.002)$ \\
\hline 2013 & $41.209^{* * *}$ & $(0.476)$ & $0.026^{* * *}$ & $(0.002)$ \\
\hline 2014 & $53.484^{* * *}$ & $(0.439)$ & $0.030^{* * *}$ & $(0.002)$ \\
\hline 2015 & $51.756^{* * *}$ & $(0.428)$ & $0.029 * * *$ & $(0.002)$ \\
\hline 2016 & $58.707^{* * *}$ & $(0.435)$ & $0.036^{* * *}$ & $(0.002)$ \\
\hline 2017 & $66.463^{* * *}$ & $(0.435)$ & $0.035^{* * *}$ & $(0.002)$ \\
\hline Constant & $57.382^{* * *}$ & $(0.354)$ & $0.048^{* * *}$ & $(0.001)$ \\
\hline Observations & 24357 & & 24357 & \\
\hline$R^{2}$ & 0.717 & & 0.062 & \\
\hline
\end{tabular}

Standard errors in parentheses ${ }^{* * *} p<0.01,{ }^{* *} p<$
based on the Household Budget Survey data.

The coefficient for total expenditure $\left(\beta^{1}\right.$ from equation (2)) is significant and indicates that the quality elasticity of expenditure is about $0.11 \%$. This result is consistent with the results from other countries (eg, Ref. ${ }^{19}$ for India; Ref. ${ }^{20}$ for Pakistan; Ref. $^{22}$ for Indonesia) and indicates that there is quality shading in Serbia. The use of Deaton's model is therefore necessary for obtaining an unbiased estimate of cigarette price elasticity.

Remaining coefficients from unit value regression have the expected signs: unit value is lower in larger households, households with higher shares of men and adults, households with lower levels of education, and in rural settlements. Additionally, pensioner households pay lower prices for cigarettes, while the opposite is true for unemployed households. Finally, cluster fixed effects are statistically significant and relatively large, thus confirming significant time and space variations of unit values.

Results from the budget share equation indicate that households with $1 \%$ higher expenditure spend about 0.002 percentage points more of their budget on cigarettes. Additionally, the budget share spent on cigarettes is larger among smaller households, in households with higher shares of men and adults, but is lower in the households where the maximum education is higher. In pensioner households, the conditional budget share is lower, while for unemployed households it is higher than in the employed households. Finally, cluster fixed effects are significant.

Estimated values of the coefficients for logarithm of total expenditure from equations (1) and (2) are used to arrive at the estimate of the total expenditure elasticity of demand, by using the formula from equation (7). The estimated value of total expenditure elasticity is, in line with the previous estimates, positive at 0.964 . In other words, among the households which consume cigarettes, a $10 \%$ higher total household expenditure is associated with the $9.6 \%$ higher quantity of cigarettes smoked.

After we calculate the second-stage variables (equations (3) and (4)), similarly to Deaton, ${ }^{19}$ we additionally purge the regional effects to account for potential differences in the tastes. We correct for these effects by regressing cluster averages of unit values and budget shares on regional dummies and then using the residuals from these equations in the second-stage calculations. Due to limited space, the results of this analysis are not presented in the paper; however, they are available upon request from the authors. In the final stage of the estimation, following equations (5) and (6), we arrive at the estimated price elasticity of the cigarettes demand. Results indicate a negative price elasticity of -0.639 . In other words, if cigarette prices in Serbia increase by $10 \%$, the demand for cigarettes will decrease by about $6.4 \%$. The SE of the elasticity, calculated via bootstrapping procedure (1000 replications), indicates that the value of

Table 3 First-stage regression results

\begin{tabular}{|c|c|c|c|c|}
\hline \multirow{2}{*}{$\begin{array}{l}\text { Variables } \\
\text { Total expenditure (In) }\end{array}$} & \multicolumn{2}{|c|}{ Unit value (per pack, In) } & \multicolumn{2}{|c|}{ Cigarettes budget share (in \%) } \\
\hline & $0.114^{* * *}$ & $(0.003)$ & $0.002^{* * *}$ & $(0.001)$ \\
\hline Household size (In) & $-0.060^{* * *}$ & $(0.003)$ & $0.003^{* * *}$ & $(0.001)$ \\
\hline Male ratio & $-0.026^{* * *}$ & $(0.005)$ & $0.018^{* * *}$ & $(0.001)$ \\
\hline Adult ratio & $-0.040^{* * *}$ & $(0.008)$ & $0.013^{* * *}$ & $(0.002)$ \\
\hline Mean education & $0.007^{* * *}$ & $(0.001)$ & 0.000 & $(0.000)$ \\
\hline Maximum education & 0.001 & $(0.001)$ & $-0.001^{* * *}$ & $(0.000)$ \\
\hline Rural settlements & $-0.023^{* * *}$ & $(0.003)$ & $0.002^{* * *}$ & $(0.001)$ \\
\hline \multicolumn{5}{|l|}{ Household type } \\
\hline Employed & omitted & & & \\
\hline Unemployed & $0.014^{* *}$ & $(0.006)$ & $0.003^{* *}$ & $(0.001)$ \\
\hline Pensioners & $-0.030^{* * *}$ & $(0.003)$ & $-0.014^{* * *}$ & $(0.001)$ \\
\hline Self-employed & 0.002 & $(0.004)$ & $-0.003^{* * *}$ & $(0.001)$ \\
\hline \multirow[t]{2}{*}{ Cluster dummies } & $F(1671,224$ & & $F(1822,60056$ & \\
\hline & $42.513^{* * *}$ & & $2.459^{* * *}$ & \\
\hline Constant & $3.198^{* * *}$ & $(0.030)$ & $0.021^{* * *}$ & $(0.008)$ \\
\hline Observations & 24143 & & 61889 & \\
\hline$R^{2}$ & 0.780 & & 0.105 & \\
\hline
\end{tabular}

Standard errors in parentheses ${ }^{* * *} \mathrm{p}<0.01,{ }^{* *} \mathrm{p}<0.05,{ }^{*} \mathrm{p}<0.1$. Authors' calculation based on the Household Budget Survey data. 
the price elasticity is significantly lower than zero $(\xi=-0.639$; $\left.\mathrm{SE}_{\xi}=0.063, \mathrm{t}=-10.1\right)$. In order to check the robustness of this result, we estimate price elasticity on three period subsamples: 2006-2009; 2010-2013; 2014-2017. Estimated elasticities for the subsamples are $-0.638,-0.595$ and -0.779 , respectively, and are all statically significant. Additionally, $95 \%$ confidence intervals of all subsample estimates contain the elasticity estimated on the overall sample $(-0.639)$. The standard errors for the subsample estimates are much larger than for the overall sample, suggesting a significant increase in precision of the estimate for using higher number of years.

\section{DISCUSSION AND CONCLUSIONS}

Serbian tobacco market is characterised by high tobacco consumption and low prices, which is at least partially the consequence of the tobacco taxation policy failing to meet the level of taxation recommended by WHO and the EU regulations. Higher prices of tobacco products are prevented by the slow (rather than faster) increase of the excise duties, which are under the influence of tobacco industry in Serbia, given the widespread and overstated belief regarding their impact on government revenues and employment.

In this paper, we provide a first reliable estimate of cigarettes price elasticity for Serbia. We use HBS data (2006-2017) for Serbia and Deaton's (1988) demand model to estimate the price elasticity of cigarettes consumption. We find a negative price elasticity of quantity demanded for cigarettes of -0.639 , which is in line with previous estimates for low-income and middleincome countries. $^{2}$

Given that the estimated price elasticity is negative and inelastic, higher taxes on tobacco could bring an in the increase of the government revenues. The positive effects on the budget are demonstrated via calculation of the effects in online supplementary appendix table A1. At the current level of excise tax of about $€ 1.25$ per pack (specific excise- $€ 0.58$, plus ad valorem excise$€ 0.67$ ), and 20\% VAT (€0.34) $)^{9}$ and with about 655 million cigarette packs sold in Serbia in 2018, the total government revenue from taxing cigarettes amounts to 1043 million euros.

In formulating the size of the excise increase, we start from the following three recommendations: (1) that the excise level should be raised to EU recommended minimum of $€ 1.8^{8}$, (2) that excise share in total price should reach $70 \%$ in accordance with the WHO convention which Serbia signed, ${ }^{10} 11$ and (3) that the increase of excise should be through the increase of the specific excise in order to avoid introduction of the lowcost brands that could neutralise the effect of excise increase. ${ }^{23}$ The increase in demand is calculated according to the formula $D_{t+1}=D_{t}\left(\xi_{p} * \Delta p[\%]\right)$, where $D_{t+1}$ is the new demand, $D_{t}$ is the current demand level, $\xi_{p}$ is the price elasticity, while $\Delta p[\%]$ is the percentage increase of real prices. The increase in government revenues is then calculated as the product of new demand and new total tax burden on cigarette pack (see online supplementary appendix table A1).

Our calculation shows that in line with these three conditions the specific excises should be raised to the level of $€ 0.95$, that is, by $63.8 \%$, while at the same time the weighted average price should be raised by $26 \%$, to $€ 2.57$. In this scenario, the demand would decrease by $16.6 \%$, while government revenue would increase by $16.6 \%$ (scenario 1 in the online supplementary file A1).

However, in this scenario, the net-of-tax producers' price would decrease, and we therefore analyse two more scenarios of the excise increase. In the second scenario, we keep the net-of-tax producers price at the same level as in the baseline scenario, while keeping the increase of the specific excises to the level of $€ 0.95$. The total price in this scenario would need to be increased by $36 \%$. The share of excise in total price would decrease to $67.2 \%$, which would be below WHO recommendation, but the total excise would be $€ 1.87$ which is above the EU recommended minimum. This change would result in demand decrease by $22.9 \%$, while government revenue would increase by $12.6 \%$ (scenario 2 in the online supplementary table A1). Finally, in the third scenario, we simulate the situation where the producers increase their net-of-tax price by $€ 0.1$, while keeping the increase of the specific excises to the level of $€ 0.95$. In this scenario, the share of excise in total price would decrease below WHO recommendation, to $64.9 \%$, while the total excise would be $€ 1.93$, again be above the EU recommended minimum). This change would result in a demand decrease by $29.3 \%$, while government revenue would increase by $7.8 \%$. Therefore, regardless of the producer's responce, the increase of excises on tobacco would results in lower demand and an increase of the government revenues.

\section{RECOMMENDATIONS}

Based on the above calculations, we recommend that specific excise should increase to $€ 0.95$ per pack, and that that increase should be immediate, and not gradual (at the rate of $4 \%$ nominally per year, this level would be reached only by 2031, the time by which probably new recommendations for the excise level would be in place). Besides this increase, the government should also make sure that other tobacco products (roll-your-own tobacco, heated tobacco, etc.) follow the same excise increase, to avoid the product substitution. The Excise $\mathrm{Law}^{9}$ already contains the provisions which adjust the excises of other tobacco products and the government should make sure that these are fully implemented. This set of measures would prevent industry from manipulating the prices of different cigarettes brands and tobacco products, and as demonstrated bring additional revenue to the government.

More importantly, decreasing demand and consumption could lower the harmful health effects of cigarettes, such as disease prevalence and mortality rates. The positive health impact could be even higher if part of the money raised through increased taxes was directed towards the reducing death and diseases from tobacco use and health promotion. ${ }^{1}$ Furthermore, lower demand and less harmful effects on health could have an additional positive effect on the budget besides the one resulting directly from the revenue collection, by lowering the health expenditures. From the wider policy perspective, the primary focus of the policy-makers should not be on the revenue side of the government budget, but rather on public health, as health is more important than material conditions for the overall wellbeing of Serbian citizens. ${ }^{24}$

\section{Limitations and future research}

As explained in the methodology section, due to methodological reasons and low reported expenditure (less than $3 \%$ of total tobacco consumption), cut tobacco is excluded from the analysis. There is a wide area for further research which could provide additional arguments for the policy reforms mainly referring to estimation of the positive effects arising from lower consumption, such as: lower health costs, increase of the labour productivity and increase of economic activity in other sectors since the money spent on tobacco would be spent on other products. 


\section{What this paper adds}

- Previous research has indicated that the tobacco price elasticity is negative and inelastic.

- Goods with inelastic elasticity simultaneously lower the demand for tobacco products and increase public revenues.

- The price elasticity of cigarettes in Serbia is estimated at -0.639 , in line with previous estimates for middle-income countries.

- Estimated elasticity suggests that tobacco tax policy could be used effectively to reduce cigarette consumption while also have positive fiscal effects.

Funding This research is funded by the University of Illinois at Chicago's Institute for Health Research and Policy through its partnership with the Bloomberg Philanthropies and the Ministry of Education, Science and Technological Development of Serbia.

Competing interests None declared.

Patient consent for publication Not required.

Provenance and peer review Not commissioned; externally peer reviewed.

Data availability statement Data were obtained from the Statistical Office of the Republic of Serbia (SORS) and cannot be shared with third parties, in accordance with the contract signed by the Insititute of Economic Sciences and SORS. The data (described in the paper) can be obtained from the SORS by request.

Author note This paper is a result of international research project 'Accelerating progress in taxation of tobacco and tobacco products in low- and middle-income countries'. Authors' research is additionally supported by the Ministry of Education, Science and Technological Development of Serbia.

ORCID iDs

Marko Vladisavljevic http://orcid.org/0000-0001-6020-1355

Jovan Zubović http://orcid.org/0000-0002-1717-2066

Mihajlo Đukić http://orcid.org/0000-0001-5677-330X

Olivera Jovanović http://orcid.org/0000-0002-0676-4787

\section{REFERENCES}

1 Chaloupka FJ, Yurekli A, Fong GT. Tobacco taxes as a tobacco control strategy. Tob Control 2012;21:172-80.

2 US. National cancer Institute and world Health organization. The economics of tobacco and tobacco control. National cancer Institute tobacco control monograph 21. NIH publication No. 16-CA-8029A. Bethesda, MD: U.S. Department of Health and Human Services, National Institutes of Health, National Cancer Institute; and Geneva, CH:World Health Organization, 2016.

3 Chaloupka FJ, TW H, Warner KE, et al. The taxation of tobacco products. In: Jha P, Chaloupka FJ, eds. Tobacco control in developing countries. Oxford and. New York: Oxford University Press, 2000: 237-72.
4 Eurostat, tobacco consumption statistics, proportion of daily smokers of cigarettes, $(\%$ persons aged 15 and over), 2014. Available: https://ec.europa.eu/eurostat/statisticsexplained/index.php/Tobacco_consumption_statistics

5 Institute of Public Health of Serbia - Batut, IOPHOS - Batut. Rezultati istraživanja O efektima I stavovima U vezi SA Zakonom 0 zaštiti stanovništva od izloženosti duvanskom dimu (results of the survey on the effects and attitudes related to the law on protection of the population from exposure to tobacco smoke) 2015. Belgrade Institute for Public Health of Serbia "Dr. Milan Jovanovic Batut".

6 Institute of Public Health of Serbia - Batut, IOPHOS - Batut. Serbia country report global youth tobacco survey (GYTS), 2017. Available: http://www.batut.org.rs/ download/izdvajamo/GYTS\%202017\%20kljucni\%20rezulatati.pdf [Accessed 12 Jun 2018].

7 Government of Serbia. Decision on the amount of average weighted retail prices and minimum excise taxes for tobacco products as of July 6th, 2018. Available: http:// duvan.gov.rs/aktuelnosti/odluka_iznosima_ponderisanih_mpc_06.07.2018

8 European Commision, EC, Excise duty tables. Part III - Manufactured Tobacco (Shows the situation as at 01/07/2018).2018. Brussels - Belgium - Office: SPA3 6/70. Available: https://ec.europa.eu/taxation_customs/sites/taxation/files/resources/ documents/taxation/excise_duties/tobacco_products/rates/excise_duties-part_iii_ tobacco_en.pdf [Accessed 18 Jan 2019].

9 Government of the Republic of Serbia. GoS, different years: law on tobacco, (official Gazette No. 101/2005, 90/2007, 95/2010, 36/2011.

10 World Health Organization. Who framework convention on tobacco control, 2004.

11 World Health Organization,. WHO technical manual on tobacco tax administration. World Health Organization, 2010.

12 SORS. Statistical office of the Republic of Serbia, statistical Yearbook - different numbers. Belgrade, statistical office of the Republic of Serbia, 2007 - 2018.

13 European Commission,. Eurostat data - decline in cigarette production, 2019. Available: https://ec.europa.eu/eurostat/web/products-eurostat-news/-/EDN20190531-1

14 National Cancer Institute and WHO, NCI Tobacco Control Monograph Series 21. The economics of tobacco and tobacco control, 2017.

15 Deaton A. Quality, quantity, and spatial variation of price. American Economic Review 1988;78:418-30.

16 SORS - Statistical Office of the Republic of Serbia. Household budget survey, 2016; Bulletin 627. Belgrade: Statistical Office of the Republic of Serbia, 2016.

17 John R, Chelwa G, et al, Using Household Expenditure Surveys for Research in the Economics of Tobacco Control. A Tobacconomics toolkit. Chicago, IL: Tobacconomics, Health Policy Center, Institute for Health Research and Policy, University of Illinois at Chicago, 2019.

18 Jovanovic O, Zubović J, Vladisavljević M, et al. Estimation of tobacco products price and income elasticity using aggregate data. Economic Analysis 2018;51:81-94.

19 John RM. Price elasticity estimates for tobacco products in India. Health Policy Plan 2008:23:200-9.

20 Deaton A. The analysis of household surveys: a Microeconometric approach to development policy. Baltimore: Johns Hopkins University Press, 1997.

21 Frisch R, Waugh FV. Partial time regressions as compared with individual trends. Econometrica 1933:1:387-401.

22 Deaton A. Price elasticities from survey data: extensions and Indonesian results. J Econ 1990:44:281-309.

23 Shang C, Chaloupka FJ, Zahra N, et al. The distribution of cigarette prices under different Tax structures: findings from the International tobacco control policy evaluation (ITC) project. Tob Control 2014;23:i23-9.

24 Vladisavljević M, Mentus V. The structure of subjective well-being and its relation to objective well-being indicators: evidence from EU-SILC for Serbia. Psychol Rep 2019;122:36-60. 